\title{
Organometallic cobalamin anticancer derivatives for targeted prodrug delivery via transcobalamin- mediated uptake $\uparrow$
}

\author{
Jeremie Rossier, ${ }^{a}$ Daniel Hauser, ${ }^{\mathrm{b}}$ Emmanuel Kottelat, ${ }^{\mathrm{a}}$ Barbara Rothen-Rutishauser ${ }^{\mathrm{b}}$ \\ and Fabio Zobi*a

\begin{abstract}
Herein we report the synthesis of new water-soluble vitamin $B_{12}$ prodrugs bearing metal complexes at the $\beta$-upper side of the cobalt center. A total of three derivatives with the general design $\{\mathrm{Co}-\mathrm{C} \equiv \mathrm{C}-\mathrm{bpy}-\mathrm{M}\}$, where $M$ represents a cytotoxic metal complex, were prepared and tested for their cytotoxicity against MCF-7 breast cancer cells. The choice of the metal was oriented on the eminent Pt and promising Ru and Re species to demonstrate the general applicability of the approach. The recognition of the derivatives by transcobalamin was demonstrated by competitive displacement assays using rhodamine labeled $\mathrm{B}_{12}$. This compound further served to prepare a dual luminescent probe by orthogonal synthesis with $M=\left((\mathrm{HCCbpy}) \mathrm{Ru}(\mathrm{bpy})_{2}\right) \mathrm{Cl}_{2}$ and to perform in vitro assays. Cellular imaging experiments allowed us to observe the different compartmentalization of both dyes and thus prove that the species follow the natural cobalamin uptake as well as the self-triggered release of the $\beta$-upper complex.
\end{abstract}

\section{Introduction}

Chemotherapeutic agents are commonly used as drugs for cancer therapy. Despite a large variety of structural motifs, most compounds lack selectivity and thus are indiscriminate between healthy and cancer tissues. As a consequence, besides a reduced efficiency, the treatment comes with a long list of unpleasant and deterring side effects. Strategies for the highly selective delivery of drugs aim to decrease off-target effects and thus ease the treatment burden for patients. To this end, the high proliferative rate of cancer cells is favorable as they overexpress numerous receptors on their surface. ${ }^{1-3}$ Exploiting this characteristic by preferentially accumulating cytotoxic compounds into malignant tissues is therefore a worthwhile objective.

Vitamin $\mathrm{B}_{12}$ (cobalamin, $\mathrm{Cbl}$ ), which has a major role in the metabolism of every cells in the human body, is a candidate for this purpose as it offers a smooth and efficient Trojan horse approach to deliver therapeutic agents. ${ }^{4-6}$ Cobalamin is actively transported to the blood stream by three different carrier proteins and ultimately taken up by the cells following

${ }^{a}$ Department of Chemistry, University of Fribourg, Chemin du Musée 9, 1700 Fribourg, Switzerland.E-mail: fabio.zobi@unifr.ch

${ }^{b}$ Adolphe Merkle Institute, Chemin des Verdiers 4, 1700 Fribourg, Switzerland $\dagger$ Electronic supplementary information (ESI) available: Detailed synthetic procedures, full characterization of the new compound and other necessary charac-terization studies. a receptor-mediated endocytosis of transcobalamin-bound $\mathrm{Cbl}$ (TCII-Cbl). ${ }^{7}$ The TCII-Cbl complex is then degraded in lysosomes and Cbl discharged into the cytosol. Successively, the Co undergoes an intracellular reduction which triggers the release of the $\beta$-axial ligand. ${ }^{8,9}$ By taking advantage of this mechanism, vitamin $\mathrm{B}_{12}$ imposes itself as an ideal vector for targeted drug delivery applications.

However, thus far, chemical modifications at the $\beta$-side of the vitamin were greatly limited by technical difficulties related to the synthesis of such analogues. In addition, the poor photo- and thermal stability specific to organometallic cobalamins possessing an alkyl, vinyl or aryl group bound to the Co atom imposed another constraint. ${ }^{7,10}$ Nevertheless, metal species such as Pt, Re and Tc complexes could be attached at this position by relying on the ability of $\mathrm{Cbl}$ to form heterodinuclear complexes of the general motif $\{\mathrm{Co}-\mathrm{CN}-\mathrm{M}\} .{ }^{11-13}$ Although remarkable, these derivatives did not release complexes of identical chemical compositions after reduction of the Co center. ${ }^{12}$ Therefore, with this strategy, assessing the efficacy of $\mathrm{Cbl}$ to deliver a cytotoxic compound is somewhat biased. However, by applying recent advances in the organometallic chemistry of Cbl described by the groups of Kräutler and Gryko, ${ }^{14,15}$ we aim to propose a simple and adjustable structural model to overcome this difficulty and stimulate the design of other motifs.

Herein we report the synthesis of new water-soluble vitamin $\mathrm{B}_{12}$ prodrugs bearing metal complexes at the $\beta$-upper side of the cobalt center. These species, which bear a common 
$\{\mathrm{Co}-\mathrm{C} \equiv \mathrm{C}-\mathrm{bpy}-\mathrm{M}\}$ moiety, are active against MCF-7 breast cancer cells and despite substantial structural modification are still recognized by the transcobalamin (TCII) carrier protein. Modification at the $5^{\prime}-\mathrm{OH}$ ribose with a rhodamine label allowed us to prepare a dual luminescent probe by orthogonal synthesis with the $\left[(\mathrm{HCCbpy}) \mathrm{Ru}(\mathrm{bpy})_{2}\right] \mathrm{Cl}_{2}$ complex and to perform in vitro cellular imaging experiments. Our results indicate that the molecules follow the natural cobalamin uptake and the prodrug is activated intracellularly via a self-triggered release of the $\beta$-upper complex.

\section{Results and discussion}

\section{Synthesis and characterization}

For the preparation of the three vitamin $\mathrm{B}_{12}$ derivatives $\left(\mathrm{B}_{12} \mathbf{- 1}\right.$, $\mathrm{B}_{12}-2$ and $\mathrm{B}_{12}-3$, Fig. 1), the initial approach consisted of attaching a bipyridyl moiety at the cobalt center of $\mathrm{Cbl}$ $\left(\mathrm{B}_{12}\right.$-bpy) in order to form the desired $\mathrm{B}_{12}$ derivatives upon reaction with metal precursors. Although successful, low yields forced to revise the approach. Therefore, the synthetic scheme was reconsidered and bipyridyl metal complexes bearing a terminal alkyne were first prepared and then reacted with $\mathrm{Cbl}$ (Fig. 1). The choice of the metal was oriented on platinum (1), ruthenium (2) and rhenium (3) owing to the cytotoxicity of several analogues readily adaptable to our needs. ${ }^{16,17}$

To ensure that the Co- $\mathrm{C}_{\mathrm{sp}}$ bond was cleaved and that the complexes were entirely released under reducing conditions, the three derivatives were individually reacted with $\mathrm{Zn}$ in $\mathrm{NH}_{4} \mathrm{Cl}(1 \%)$. After reoxidation in air, the reaction mixtures were analysed by HPLC and each fraction was identified by its mass (Fig. 2). In each case, the presence of $\mathrm{H}_{2} \mathrm{OCbl}$ testified to
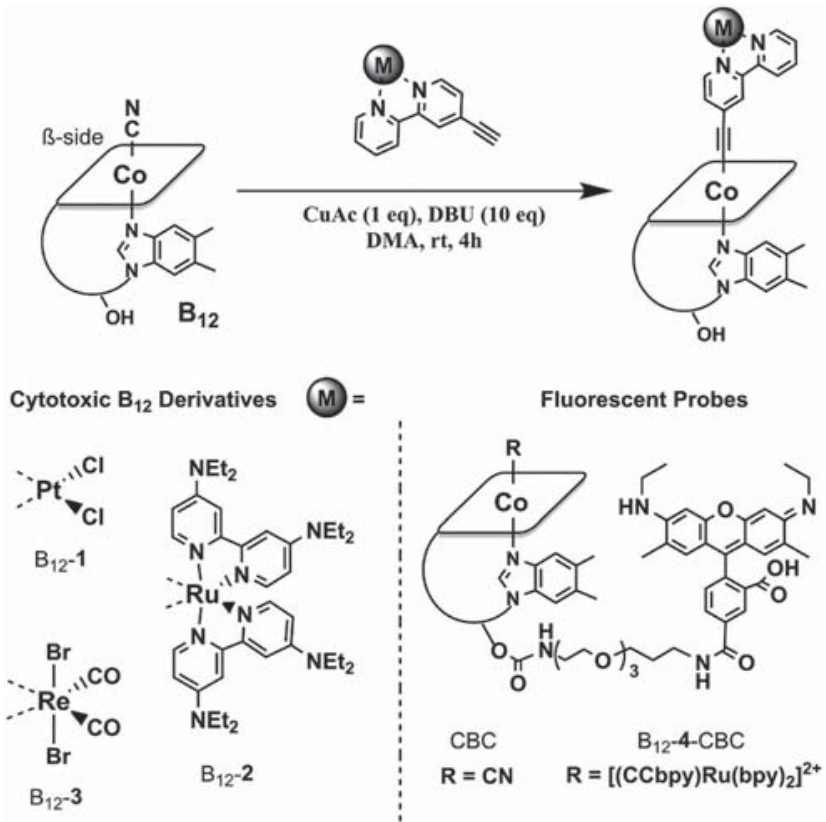

Fig. 1 Synthetic scheme and the structures of vitamin $B_{12}$ derivatives.

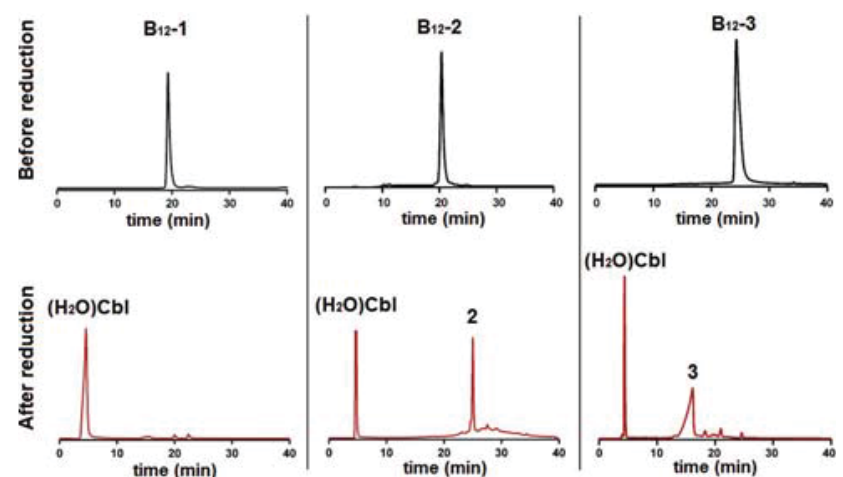

Fig. 2 Chemical reduction of the derivatives $B_{12}-1$ to -3 (from left to right). HPLC chromatograms before the reduction (above) and after the reduction (bellow). The reduction has triggered the release of complexes 1 (filtered prior to injection due to its insolubility), 2 and 3 . The formation of $\mathrm{H}_{2} \mathrm{OCbl}$ was observed in each case. HPLC conditions are described in the Experimental part.

the successful metal complex release and the intact nature of complexes 2 and 3 could be confirmed by HPLC-MS analysis.

However, due to its poor aqueous solubility, 1 precipitated soon after the reduction step and its structure was confirmed by NMR analysis. Interestingly, this observation further emphasizes the ability of vitamin $\mathrm{B}_{12}$ to greatly increase the aqueous solubility of compounds that might otherwise have little ability to be used as a drug. ${ }^{18}$

From a stability point of view, no proteolytic detachment of the complexes was observed under mild acidic conditions ( $\mathrm{pH} 3$ to 7 ) within 24 hours. The derivatives $\left(\mathrm{B}_{12}-\mathbf{1}, \mathrm{B}_{12}-\mathbf{2}\right.$ and $\left.\mathrm{B}_{12}-3\right)$ were remarkably photostable even after several days of daylight exposure, which is consistent with observations reported for ethynylcobalamin ${ }^{19}$ and other acetylide cobalamins. ${ }^{14,15,20}$

\section{Plasma stability and transcobalamin binding}

In order to assess their plasma stability, we evaluated the interaction of $\mathrm{B}_{12}-\mathbf{1}, \mathrm{B}_{12}-2$ and $\mathrm{B}_{12}-\mathbf{3}$ with human serum albumin under physiological conditions. The tests were performed over a $24 \mathrm{~h}$ period and the mixtures were analysed by HPLC (Fig. 3). The results indicate that respectively $c a .39 \%$ and $60 \%$ of $\mathrm{B}_{12}-1$ and $\mathrm{B}_{12}-3$ were bound to HSA after 1 day while $\mathrm{B}_{12}-2$ showed no interaction with the protein. For $\mathrm{B}_{12}-\mathbf{1}$ the results were somewhat expected, since the interaction of cisplatin analogues with HSA has been extensively reported. ${ }^{21,22}$ Similarly, the behaviour of $\mathrm{B}_{12}-2$ is in accordance with the free, electronrich analogues of $2 .^{23}$ As for $\mathrm{B}_{12}-3$, the lack of such studies involving equivalent rhenium carbonyl complexes prevents this comparison. In general, we could reasonably argue that the HSA interaction of our derivatives might be minimized in vivo, since it was demonstrated that vitamin $\mathrm{B}_{12}$ is buried deep inside the transcobalamin structure once bound. ${ }^{24}$

To be actively carried, the derivatives must be recognized by transcobalamin. Whereas three carrier proteins are involved in the transport of $\mathrm{Cbl}$, the transcobalamin-Cbl complex (TCII-Cbl) 

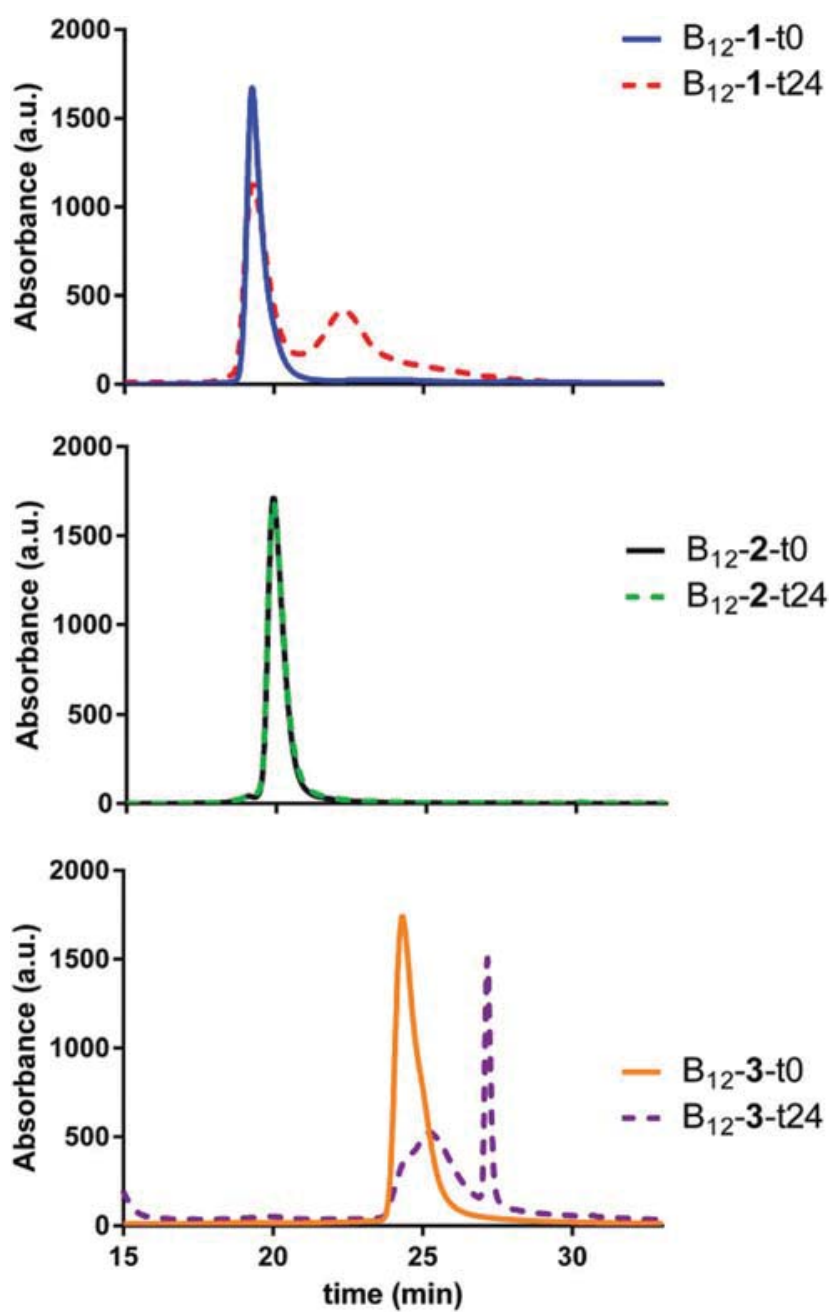

Fig. 3 Human serum albumin (HSA) stability of the derivatives $B_{12}-1$ to -3. The overlap of HPLC chromatograms immediately after HSA-B12-\# derivative mixture preparation ( $t 0)$ and after one day (t24).

is ultimately taken up by cells via receptor-mediated endocytosis. Therefore, we focused on this interaction and a competitive assay using rhodamine labelled $\mathrm{B}_{12}$ (CBC, Fig. 1) was performed as previously established. ${ }^{25}$ Indeed, since the CBC interaction with TCII induces an enhancement of its luminescence intensity, the binding of competitive Cbl derivatives can be directly monitored. The addition of TCII-recognized $\mathrm{B}_{12}$ analogues quenches the luminescence of the TCII-CBC complex in proportion to the level of competition established. The presence of $\mathrm{Cbl}$ showed the highest competition level, while for our derivatives, various degrees of quenching (i.e. binding) were observed, in the following order: $\mathrm{B}_{12}-3>\mathrm{B}_{12}-2>$ $\mathrm{B}_{12}-\mathbf{1}$ (Fig. 4).

\section{Cytotoxicity against MCF-7 breast cancer cells}

We then considered whether the relative TCII binding of our derivatives might be reflected in their biological activity. Thus, the cytotoxicity of $\mathrm{B}_{12}-\mathbf{1}$ to $\mathbf{- 3}$ was evaluated using the MCF-7 breast cancer cell line. It is worth noting that this cell line is

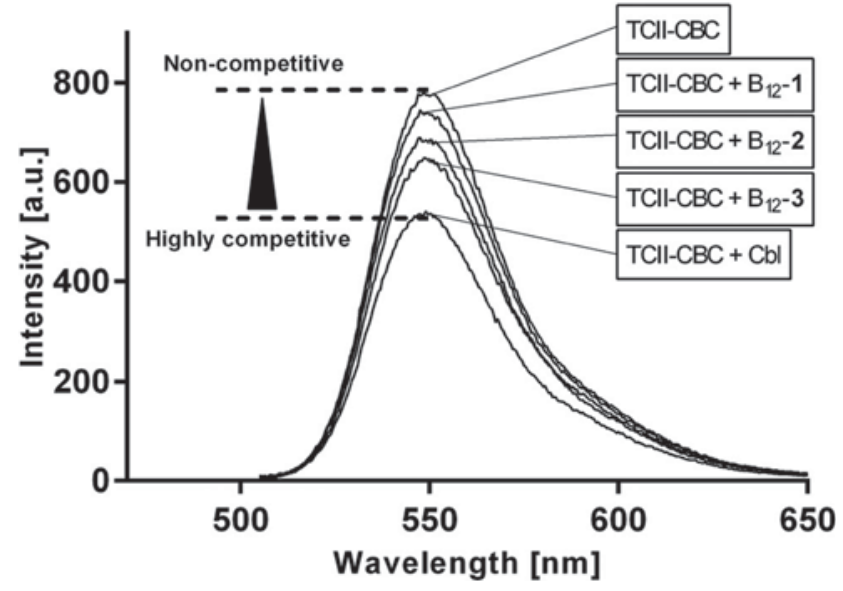

Fig. 4 Fluorescence quenching of the TCII-CBC complex emission induced by equimolar addition of derivatives $B_{12}-1$ to -3 and of natural Cbl.

appropriate to evaluate the activity of $\mathrm{Cbl}$ derivatives since it excretes a high level of TCII as well as the respective membrane receptor. ${ }^{26}$ Table 1 shows the $\mathrm{IC}_{50}$ values of the free (unbound) complexes 1-3 and of their corresponding $B_{12}$ species. As can be seen, the cytotoxicity of the derivatives is lower than one of their free counterparts 1-3. The difference might be explained by a different uptake mechanism. In the case of $\mathrm{B}_{12}-\mathbf{1}$ to $-\mathbf{3}$, an active transport suggests a transitory internalization into lysosomes (vide infra and ESI $\dagger$ ). For such prodrugs, this stage likely prevents their activation through the release of the $\beta$-upper ligand until their lysosomal discharge. Taken separately, the cytotoxicity of the complexes shows that 1, 2 and 3 exhibit $\mathrm{IC}_{50}$ values below $10 \mu \mathrm{M}$. In interpreting the value of $\mathbf{1}$, it must be considered that dissolving platinum complexes in DMSO often results in ligand displacement and changes to the structure of the complex. ${ }^{27,28}$ However, due to its very low aqueous solubility, a dissolution in DMSO ( $0.1 \%$ final concentration) was necessary. The activity of $\mathbf{3}$ is remarkable since its $\mathrm{IC}_{50}$ of $1.4 \mu \mathrm{M}$ is lower than cisplatin. Except for this latter complex, for which no example of similar analogues exists, the $\mathrm{IC}_{50}$ values of $\mathbf{1}$ and $\mathbf{2}$ are consistent with the reported values for similar species under comparable conditions. ${ }^{16,17}$ Interestingly, the order of magnitude that differentiates the toxicity of the complexes compared to their respect-

Table 1 Cytotoxicity of complexes 1-3 and the corresponding $B_{12}$ derivatives $\mathrm{B}_{12}-1$ to -3 toward MCF-7 cells

\begin{tabular}{|c|c|c|c|}
\hline \multicolumn{2}{|c|}{ Free complexes } & \multicolumn{2}{|c|}{ Vitamin $\mathrm{B}_{12}$ derivatives } \\
\hline Compound & $\mathrm{IC}_{50}[\mu \mathrm{M}]$ & Compound & $\mathrm{IC}_{50}[\mu \mathrm{M}]$ \\
\hline 1 & $5.0 \pm 2.4$ & $\mathrm{~B}_{12}-1$ & $29.0 \pm 5.2$ \\
\hline 2 & $3.2 \pm 1.1$ & $\mathrm{~B}_{12}-2$ & $10 \pm 3.3$ \\
\hline 3 & $1.4 \pm 0.3$ & $\mathrm{~B}_{12}-3$ & $6.3 \pm 0.4$ \\
\hline
\end{tabular}

Cisplatin (CDDP) $3.7 \pm 1.2 \mu \mathrm{M}$. 
ive $\mathrm{Cbl}$ derivatives is in accordance with TCII recognition of the latter.

\section{Cellular localization}

In order to investigate the cellular internalization of the derivatives, a dual luminescent compound ( $\mathrm{B}_{12}-\mathrm{4}-\mathrm{CBC}$, Fig. 1) was prepared. Owing to its relative non-toxicity as well as for its luminescence properties, ${ }^{17}$ a ruthenium trisbipyridyl moiety was attached on the CBC scaffold at the vitamin $\beta$-side. MCF-7 cells were incubated with the compound and laser scanning microscopy was used to probe its localization. After one hour, the compound accumulated inside round shaped vesicles (Fig. 5). After $24 \mathrm{~h}$ of exposure, both signals could be detected inside the cytosol as well. However, their respective localization was offset suggesting different pathways of the fluorophores (Fig. 6). These observations were supported by the use of dyes for different cell compartments.

The signals corresponding to the ruthenium and rhodamine moieties co-localized well with commercial LysoTracker (Fig. 7A). Furthermore, the rhodamine signal overlapped with MitoTracker to a higher degree than that of the ruthenium trisbipyridyl complex (Fig. 7B), which indicates reductive $\mathrm{Co}-\mathrm{C}_{\mathrm{sp}}$ bond cleavage and that the $\beta$-bound complex was successfully released in the cytoplasm. This constitutes a strong indication
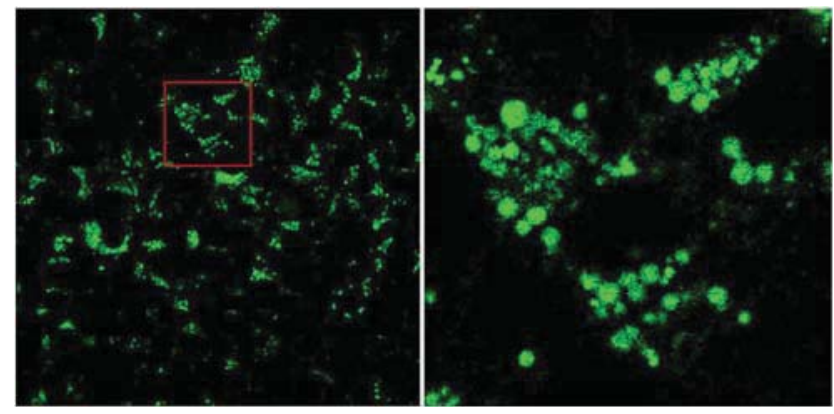

Fig. 5 Left, rhodamine emission of compound $B_{12}-4-C B C$ after $1 \mathrm{~h}$ of incubation with MCF-7 cells, and right, the magnified area of the red box showing the formation of round-shaped vesicles.
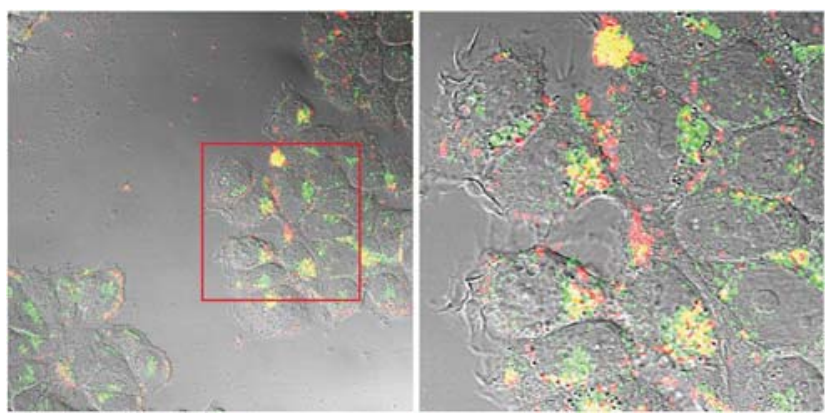

Fig. 6 Left, co-localization images of Ru and Rho signals in MCF7 cells after $24 \mathrm{~h}$ of incubation with $\mathrm{B}_{12}-4-\mathrm{CBC}$ and right, the magnified area of the red box. The Ru and Rho signals are partially offset, suggesting different pathways of the fluorophores.

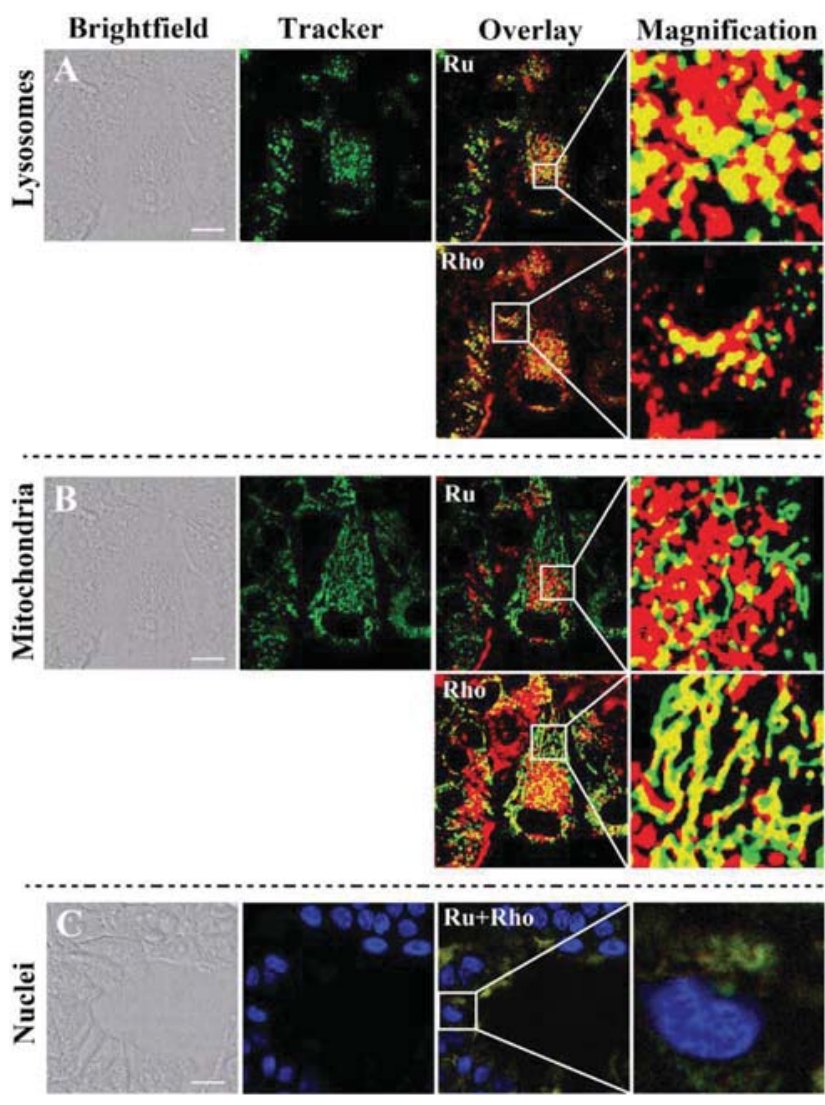

Fig. 7 Co-localization images of $\mathrm{B}_{12}-4-\mathrm{CBC}$ ruthenium $(\mathrm{Ru})$ and rhodamine (Rho) moieties emission with (A) lysosomal, (B) mitochondrial and (C) nuclear dyes in live MCF-7 cells. In order to aid the interpretation of the images, compartment stains are shown in green in (A) and (B), $\mathrm{Ru}$ and Rho signals are split and are both shown in red. Overlapping $\mathrm{Ru}$ and Rho fluorescence to dyes are yellow in magnified areas. Scale bars $=20 \mu \mathrm{m}$.

that, despite substantial structural modifications, the vitamin $\mathrm{B}_{12}$ derivative follows a similar pathway to that of the natural vitamin. Finally, none of the signals co-localized with the nuclear tracker (Fig. 7C). Taken together the results indicate an active transport of $\mathrm{B}_{12}-\mathbf{4}$-CBC, a fact that was re-emphasized by low temperature incubation of the derivative, showing a significantly lower uptake than under normal incubation conditions (ESI $\dagger$ ).

\section{Conclusions}

In summary, we have reported the synthesis of three vitamin $\mathrm{B}_{12}$ derivatives ( $\mathrm{B}_{12}-\mathbf{1}$ to $\left.\mathbf{- 3}\right)$ designed as anticancer prodrugs. An in vitro cytotoxicity assay against MCF-7 breast cancer cells showed that the vitamins could be considered as valid vectors for drug targeted delivery applications. Furthermore, despite substantial structural modification at the $\beta$-upper side, the derivatives were still recognized by the TCII carrier protein, which is a determining step toward their active transport. Such a mechanism was confirmed by fluorescent imaging experi- 
ments in live cells. The same further indicated that, after lysosomal discharge, a triggered release of the $\beta$-upper complex occurs while $\mathrm{H}_{2} \mathrm{OCbl}$ preferentially accumulates into mitochondria. We believe this strategy could provide a concrete synthetic option to the formulation of anticancer prodrugs.

\section{Experimental}

\section{General experimental details}

All chemicals were purchased from Sigma-Aldrich (St Louis, MO) and used without further purification. The protein transcobalamin (TCII) was purchased from Bio-Techne AG (Switzerland). The ligand 4-ethynyl-2,2'-bipyridine was synthesized according to a published procedure ${ }^{29}$ as well as the ruthenium complex $\left[\mathrm{Ru}(\mathrm{HCC}-\mathrm{bpy})(\mathrm{bpy})_{2}\right]\left(\mathrm{PF}_{6}\right)_{2} \cdot{ }^{30}$ MitoTracker deep red FM, LysoTracker blue DND-22 and Hoechst 33342 were bought from Life Technologies. Stock solutions of the $B_{12}-1$ to -3 species were prepared in PBS and proved to be stable for at least two days according to UV-VIS and MS spectroscopy. These compounds were stored at $-20{ }^{\circ} \mathrm{C}$, thawed and diluted in RPMI media prior to their use in biological experiments. Human breast adenocarcinoma MCF-7 cells were obtained from the Department of Medicine at the University of Fribourg (Switzerland). The cells were maintained in Gibco's RPMI 1640 medium supplemented with $10 \%$ FBS, $1 \%$ penicillinstreptomycin, $10 \mu \mathrm{g} \mathrm{mL} \mathrm{m}^{-1}$ bovine insulin at $37{ }^{\circ} \mathrm{C}$ with $5 \% \mathrm{CO}_{2}$.

HPLC analyses were performed on a Merck-Hitachi L7000. The analytical separations were conducted on a MachereyNagel Nucleodur PolarTec column $(5 \mu \mathrm{m}$ particle size, $110 \AA$ pore size, $250 \times 3 \mathrm{~mm}$ ). The preparative separations were conducted on a Macherey-Nagel Nucleodur C18 HTec column (5 $\mu \mathrm{m}$ particle size, $110 \AA$ A pore size, $250 \times 21 \mathrm{~mm}$ ). HPLC solvents were aqueous trifluoroacetic acid $0.1 \%$ (A) and methanol (B). The compounds were separated using the following gradient: 0-5 $\min (75 \%$ solvent $\mathrm{A}), \quad 5-35 \quad(75 \%$ solvent $\mathrm{A} \rightarrow 0 \%$ solvent A), 35-45 min (100\% solvent B). The flow rate was set to $0.5 \mathrm{ml} \mathrm{min}{ }^{-1}$ for analytical separations and $5 \mathrm{ml} \mathrm{min}^{-1}$ for the preparative ones. The eluting bands were detected at $320 \mathrm{~nm}$. High resolution ESI-MS was performed on a Bruker FTMS 4.7-T Apex II and the measurements were recorded in the positive mode while a Bruker UltrafleXtreme was used for MALDI-TOF experiments. Elemental analyses were performed on a LECO TruSpec CHNS(O)-micro analyser. NMR analyses were recorded on a Bruker Avance III $500 \mathrm{MHz}$. The corresponding ${ }^{1} \mathrm{H}$ and ${ }^{13} \mathrm{C}$ chemical shifts are reported relative to residual solvent protons and carbons while ${ }^{195} \mathrm{Pt}$ was referred to as $\mathrm{Na}_{2}\left[\mathrm{PtCl}_{6}\right]$. The UV/Vis spectra were recorded on a Jasco V-730 and the emission on a spectrofluorometer FS5 (Edinburgh Instruments Ltd). Measurements of the solubilized formazan were performed using a microplate reader Hidex 425-301. Cell imaging was performed using a laser confocal scanning microscope (LCSM 710, Carl Zeiss, Göttingen, Germany) with a $63 \times$ oil-immersion objective lens and equipped with an incubation chamber providing controlled temperature, moisture and $\mathrm{CO}_{2}$ atmosphere.
General procedure for the synthesis of the vitamin B12 derivatives

The following procedure was adapted from the literature to achieve the synthesis of the $\mathrm{B}_{12}$ derivatives. ${ }^{15} \mathrm{~A}$ mixture of cyanocobalamin (60 mg, $0.04 \mathrm{mmol}, 1$ eq.), CuAcO (7 mg, $0.004 \mathrm{mmol}, 0.1$ eq.) and the respective alkynes $(0.2 \mathrm{mmol}$, 5 eq.) in DMA $(10 \mathrm{ml})$ was stirred until dissolution. DBU ( $0.03 \mathrm{ml}, 0.21 \mathrm{mmol}, 5$ eq.) was added and the solution was allowed to react at room temperature for $4 \mathrm{~h}$. The respective crudes were precipitated by dropwise addition to the stirred solutions of diethyl ether/ $\mathrm{CH}_{2} \mathrm{Cl}_{2}(150 \mathrm{ml}, 1: 1)$. With the exception of $\mathrm{B}_{12}-2$ (vide infra), after filtration, the residue was dissolved in a mixture of $\mathrm{CH}_{3} \mathrm{OH}$ and water $(2 \mathrm{ml}, 1: 1)$, filtered again and purified by preparative HPLC. The eluting bands containing the desired products were isolated and lyophilized.

\section{Cellular localization assay}

MCF-7 cells were incubated in cell chamber slides $\left(1.7 \mathrm{~cm}^{2}\right.$ per well) with $\mathrm{B}_{12}-\mathbf{4}-\mathrm{CBC}(12.5 \mu \mathrm{M})$ at $37^{\circ} \mathrm{C}$ for 1 or $24 \mathrm{~h}$ and then co-incubated with MitoTracker deep red FM (150 nM, MTDR), LysoTracker blue DND-22 (150 nM, LTB) or Hoechst 33342 ( 2 drops per $\mathrm{ml}$ ) at $37^{\circ} \mathrm{C}$ for $0.5 \mathrm{~h}$. Successively, the cells were washed three times with PBS and immediately visualized by laser confocal scanning microscopy (LSCM 710, Carl Zeiss, Göttingen, Germany) with a $63 \times$ oil-immersion objective lens. The excitation wavelengths of $\mathrm{B}_{12}-\mathbf{4}-\mathrm{CBC}$ were $458 \mathrm{~nm}$ for the ruthenium moiety $(\mathrm{Ru})$ and $488 \mathrm{~nm}$ for the rhodamine moiety (Rho), while the excitation wavelength of Hoechst 33342 and LTB was $405 \mathrm{~nm}$ (in separated chambers) and $633 \mathrm{~nm}$ for MTDR. Emission filters for the trackers were set to: $450 \pm 30 \mathrm{~nm}$ for Hoechst 33342 and LTB, $700 \pm 30 \mathrm{~nm}$ for MTDR. Emission filters for $\mathrm{B}_{12}-4$-CBC were set to: $540 \pm 25 \mathrm{~nm}$ for the Rho and $660 \pm 30 \mathrm{~nm}$ for the Ru moiety.

\section{Cytotoxicity assay}

The $\mathrm{IC}_{50}$ values were determined using the breast cancer cell line MCF-7. The cells were cultured using Gibco's RPMI 1640 medium supplemented with $10 \%$ FBS, 1\% penicillinstreptomycin, $10 \mu \mathrm{g} \mathrm{mL} \mathrm{mL}^{-1}$ bovine insulin at $37{ }^{\circ} \mathrm{C}$ with $5 \%$ $\mathrm{CO}_{2}$, seeded in 96-well plates at a density of $2 \times 10^{3}$ cells per well and allowed to settle for $24 \mathrm{~h}$. After removal of the growth medium, the cells were treated with $B_{12}-\mathbf{1}$ to $-\mathbf{3}(0$ to $50 \mu \mathrm{M})$ for $72 \mathrm{~h}$. Subsequently, the cells were washed three times with PBS and fresh media were added. Each well was then completed with $20 \mu \mathrm{l}$ of MTT solution $\left(5 \mathrm{mg} \mathrm{ml}^{-1}\right.$ ) and the plates were incubated for $3-4 \mathrm{~h}$ at $37{ }^{\circ} \mathrm{C}$. After removal of the media, $100 \mu \mathrm{l}$ of DMSO were added as the MTT solvent and the plates were re-incubated at $37^{\circ} \mathrm{C}$ for another $2 \mathrm{~h}$. The solubilized formazan was quantified at $570 \mathrm{~nm}$ using a microplate reader.

\section{Stability in human serum albumin}

To a solution of human serum albumin $(150 \mu \mathrm{M})$ in phosphate buffer (0.1 $\mathrm{M}$ at $\mathrm{pH} 7.5)$ and $0.9 \% \mathrm{NaCl}$, the derivatives (1 eq.) 
were added and the solutions were gently shaken over 24 hours. Fractions were collected and analyzed via HPLC.

\section{Drug release}

The derivatives $\left(\mathrm{B}_{12}-\mathbf{1}\right.$ to $\left.-\mathbf{3}, 200 \mu \mathrm{mol}\right)$ were reacted in a $\mathrm{NH}_{4} \mathrm{Cl}$ ( $1 \%$ solution) with $\mathrm{Zn}$ dust $(0.5 \mathrm{~g})$ under a $\mathrm{N}_{2}$ atmosphere for a period of $30 \mathrm{~min}$. Methanol was added $(25 \%$ of the total final volume) and the crude solution mixtures were then analyzed via HPLC and the peaks were identified using electrospray ionization mass spectrometry (ESI-MS).

\section{Acknowledgements}

Financial support from the Swiss National Science Foundation (Grant\# PP00P2_144700) is gratefully acknowledged. D. H. and B. R. R. acknowledge the support by the Swiss National Science Foundation through the National Centre of Competence in Research "Bio-Inspired Materials" and the Adolphe Merkle Foundation.

\section{Notes and references}

1 R. T. Dorsam and G. S. Gutkind, Nat. Rev. Cancer, 2007, 7, 79-94.

2 R. I. Nicholson, J. M. Jee and M. E. Harper, Eur. J. Cancer, 2001, 37, 9-15.

3 A. Gschwind, O. M. Fisher and A. Ullrich, Nat. Rev. Cancer, 2004, 4, 361-370.

4 J. A. Bauer, B. H. Morrison, R. W. Grane, B. S. Jacobs, S. Dabney, A. M. Gamero, K. A. Carnevale, D. J. Smith, J. Drazba, B. Seetharam and D. J. Lindner, J. Natl. Cancer Inst., 2002, 94, 1010-1019.

5 D. A. Collins, P. C. Hogenkamp, M. K. O’Connor, S. Naylor, L. M. Benson, T. J. Hardyman and L. M. Thorson, Mayo Clin. Proc., 2000, 75, 568-580.

6 R. Waibel, H. Treichler, N. G. Schaefer, D. R. van Staveren, S. Mundwiler, S. Kunze, M. Küenzi, R. Alberto, J. Nüesch, A. Knuth, H. Moch, R. Schibli and P. A. Schubiger, Cancer Res., 2008, 68, 2904-2911.

7 C. Kratky and B. Kräutler, in Chemistry and Biochemistry of B12, ed. R. Banerjee, John Wiley and Sons, New York, 1999.

8 M. V. Fonseca and J. C. Escalante-Semerena, J. Bacteriol., 2000, 182, 4304-4309.

9 P. Ruiz-Sánchez, S. Mundwiler, B. Spingler, N. R. Buan, J. C. Escalante-Semerena and R. Alberto, J. Biol. Inorg. Chem., 2008, 13, 335-347.
10 K. Ó. Proinsias, M. Giedyk and D. Gryko, Chem. Soc. Rev., 2013, 42, 6605-6019.

11 S. Mundwiler, B. Spingler, P. Kurz, S. Kunze and R. Alberto, Chem. - Eur. J., 2005, 11, 4089-4095.

12 P. Ruiz-Sánchez, C. König, S. Ferrari and R. Alberto, J. Biol. Inorg. Chem., 2011, 16, 33-44.

13 S. Kunze, F. Zobi, P. Kurz and R. Alberto, Angew. Chem., Int. Ed., 2004, 43, 5025-5029.

14 M. Ruetz, R. Salchner, K. Wurst, S. Fedosov and B. Kräutler, Angew. Chem., Int. Ed., 2013, 52, 11406-11409.

15 M. Kromiński, A. Lewalska and D. Gryko, Chem. Commun., 2013, 49, 11406-11408.

16 V. Vo, Z. G. Kabuloglu-Karayusuf, S. W. Carper, B. L. Bennett and C. Evilia, Bioorg. Med. Chem., 2010, 18, 1163-1170.

17 O. Zava, S. M. Zakeeruddin, C. Danelon, H. Vogel, M. Grätzel and P. J. Dyson, ChemBioChem, 2009, 10, 17961800.

18 S. M. Clardy, D. G. Allis, T. J. Fairchild and R. P. Doyle, Expert Opin. Drug Delivery, 2011, 8, 127-140.

19 J. M. Pratt, Inorganic Chemistry of Vitamin B12, Academic Press, New York, 1972.

20 M. Chromiński, A. Lewalska, M. Karczewski and D. Gryko, J. Org. Chem., 2014, 79, 7532-7542.

21 A. I. Ivanov, J. Christodoulou, J. A. Parkinson, K. J. Barnham, A. Tucker, J. Woodrow and P. J. Sadler, J. Biol. Chem., 1998, 273, 14721-14730.

22 G. Ferraro, L. Massai, L. Messori and A. Merlino, Chem. Commun., 2015, 51, 9436-9439.

23 H. Huang, B. Yu, P. Zhang, J. Huang, Y. Chen, G. Gasser and L. Ji, Angew. Chem., Int. Ed., 2015, 54, 14049-14052.

24 K. Gruber, B. Puffer and B. Kräutler, Chem. Soc. Rev., 2011, 40, 4346-4363.

25 S. N. Fedosov, C. B. Grissom, N. U. Fedosova, S. K. Moestrup, E. Nex and T. E. Petersen, FEBS J., 2006, 273, 4742-4753.

26 A. M. Sysel, V. E. Valli, R. B. Nagel and J. A. Bauer, Anticancer Res., 2013, 33, 4203-4212.

27 W. I. Sundquist, K. J. Ahmed, L. S. Holis and S. J. Lippard, Inorg. Chem., 1987, 26, 1524-1528.

28 M. D. Hall, K. A. Telma, K.-E. Chang, T. D. Lee, J. P. Madigan, J. R. Lloyd, I. S. Goldlust, J. D. Hoeschele and M. M. Gottesman, Cancer Res., 2014, 74, 3913-3922.

29 A. Baron, C. Herrero, A. Quaranta, M. Charlot, W. Leibl, B. Vauzeilles and A. Aukauloo, Inorg. Chem., 2012, 51, 5985-5987.

30 C. Herrero, A. Quaranta, S. El Ghachtouli, B. Vauzeilles, W. Leibl and A. Aukauloo, Phys. Chem. Chem. Phys., 2014, 16, 12067-12072. 